\title{
Food system stress-test
}

Resilience of the food system is being tested by the COVID-19 pandemic. We must take stock, learn — and transform.

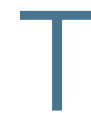

he COVID-19 pandemic has hit the food system hard. It's a global crisis, played out as much in the aisles of the supermarket as the corridors of government.

Our reliance on a small number of large retailers is evident. The pandemic has exposed their power, our dependence on their just-in-time logistics, and the responsibility divested to them for feeding the public in a crisis. But it has also exposed the valued place of the supermarket in today's society, where we turn for sustenance, where work is considered 'front-line', and where small acts of compassion have been shown to the most vulnerable amongst us.

Tied into that, we must ask serious questions about where our food is produced - would local or global food production enhance resilience? In last month's issue, Jill Edmondson and colleagues showed that growing fruit and vegetables in $10 \%$ of a UK city's gardens and other urban green spaces could provide $15 \%$ of the local population with their daily fruits and vegetables. In this issue, Pekka Kinnunen and colleagues show that less than one-third of the world's population can meet their demand for specific crops within a $100-\mathrm{km}$ radius; for up to two-thirds of the world's population, that distance is greater than $1,000 \mathrm{~km}$.

It is a time to take stock of all this - and more. This COVID-19 stress-test presents an opportunity for serious thought about transformation of the food system.

Published online: 17 April 2020 https://doi.org/10.1038/s43016-020-0071-4 